\title{
Endoscopic versus stereotactic biopsies of intracranial lesions involving the ventricles
}

\author{
Marcin Birski $^{1}$ (D) Jacek Furtak ${ }^{1} \cdot$ Kamil Krystkiewicz $^{1} \cdot$ Julita Birska $^{1} \cdot$ Karolina Zielinska $^{1} \cdot$ Paweł Sokal $^{2}$. \\ Marcin Rusinek $^{2}$ - Dariusz Paczkowski ${ }^{2} \cdot$ Lukasz Szylberg $^{3,4,5} \cdot$ Marek Harat $^{1}$
}

Received: 30 March 2020 / Revised: 8 August 2020 / Accepted: 17 August 2020 / Published online: 21 August 2020

(C) The Author(s) 2020, corrected publication 2021

\begin{abstract}
Stereotactic biopsies of ventricular lesions may be less safe and less accurate than biopsies of superficial lesions. Accordingly, endoscopic biopsies have been increasingly used for these lesions. Except for pineal tumors, the literature lacks clear, reliable comparisons of these two methods. All 1581 adults undergoing brain tumor biopsy from 2007 to 2018 were retrospectively assessed. We selected 119 patients with intraventricular or paraventricular lesions considered suitable for both stereotactic and endoscopic biopsies. A total of 85 stereotactic and 38 endoscopic biopsies were performed. Extra procedures, including endoscopic third ventriculostomy and tumor cyst aspiration, were performed simultaneously in 5 stereotactic and 35 endoscopic cases. In 9 cases ( 5 stereotactic, 4 endoscopic), the biopsies were nondiagnostic (samples were nondiagnostic or the results differed from those obtained from the resected lesions). Three people died: 2 ( 1 stereotactic, 1 endoscopic) from delayed intraventricular bleeding and 1 (stereotactic) from brain edema. No permanent morbidity occurred. In 6 cases (all stereotactic), additional surgery was required for hydrocephalus within the first month postbiopsy. Rates of nondiagnostic biopsies, serious complications, and additional operations were not significantly different between groups. Mortality was higher after biopsy of lesions involving the ventricles, compared with intracranial lesions in any location $(2.4 \%$ vs $0.3 \%, p=0.016)$. Rates of nondiagnostic biopsies and complications were similar after endoscopic or stereotactic biopsies. Ventricular area biopsies were associated with higher mortality than biopsies in any brain area.
\end{abstract}

Keywords Biopsy $\cdot$ Brain tumors $\cdot$ Hydrocephalus $\cdot$ Neuroendoscopy $\cdot$ Stereotactic techniques

\section{Introduction}

Biopsies of brain tumors involving the ventricular system require careful planning. Tissue samples from this area can be

Marcin Birski

mbirski@gmail.com

1 Neurosurgery Department, 10th Military Research Hospital, ul. Powstancow Warszawy 5, 85-681 Bydgoszcz, Poland

2 Department of Neurosurgery and Neurology, Jan Biziel University Hospital Collegium Medicum Nicolaus Copernicus University, Bydgoszcz, Poland

3 Department of Clinical Pathomorphology, Collegium Medicum Nicolaus Copernicus University, Bydgoszcz, Poland

4 Department of Tumor Pathology and Pathomorphology, Oncology Center, Bydgoszcz, Poland

5 Department of Pathomorphology, 10th Military Research Hospital, Bydgoszcz, Poland obtained using stereotactic or endoscopic methods. With stereotactic biopsies, the long trajectory and potential need to traverse the ependyma may increase the risk of intraventricular bleeding and reduce accuracy. Because of this, endoscopic biopsies have become increasingly used. During endoscopic procedures, the site of tissue collection and any areas of bleeding are continuously visualized. Furthermore, endoscopic procedures also allow simultaneous treatment of hydrocephalus, in addition to tissue sampling.

At the end of the twentieth century, stereotactic biopsy was recognized as an effective and safe method for diagnosing brain tumors and became the gold standard for diagnosis. In a metaanalysis published in 1998, Hall et al. reported $0.7 \%$ mortality and $3.5 \%$ morbidity rates after stereotactic biopsy of intracranial lesions [9]. However, more recent United States registry data suggest that the death rate is approximately $3 \%$ with this procedure $[14,20]$. In studies containing over 100 patients, endoscopic biopsy was associated with lower mortality 
rates, in the range of $0.0-0.3 \%$, and complication rates of $11.2-12.9 \%[5,12]$. By contrast, a metaanalysis by Somji et al. [24], published in 2015, revealed a mortality rate of $2.2 \%$ and a major morbidity rate of $3.1 \%$ with endoscopic biopsy.

Despite the aforementioned data, no reliable published study has directly compared outcomes associated with the two biopsy methods or described the results of stereotactic biopsies of intracranial tumors involving ventricles. We therefore conducted a study to compare outcomes, including diagnostic effectiveness and complication rates, between endoscopic and stereotactic biopsies of lesions in this area.

\section{Methods}

\section{Patients}

\section{Inclusion criteria}

Data from all 1581 adults undergoing brain tumor biopsy at our institution between 2007 and 2018 were assessed for possible inclusion in this retrospective analysis. Of these, 211 patients had intracranial tumors involving the ventricles. A team of neurosurgeons experienced in stereotactic and endoscopic methods assessed their pretreatment imaging data and selected 119 patients with intraventricular or paraventricular tumors considered suitable for either stereotactic or endoscopic biopsy. In patients with multiple similar tumors, at least one tumor must have been suitable for stereotactic biopsy, and at least one tumor must have been suitable for endoscopic biopsy.

Tumors were considered intraventricular if the stereotactic biopsy trajectory passed through the ventricle (e.g., tumors of the septum pellucidum or foramen of Monro). Conversely, tumors were considered paraventricular if the stereotactic biopsy trajectory did not pass through the ventricle (e.g., thalamic tumors).

\section{Exclusion criteria}

The following exclusion criteria were applied: tumor not associated with the ventricular system; tumor not suitable for both endoscopic and stereotactic biopsies, in patients with a single tumor; lack of at least one tumor suitable for each type of biopsy, in patients with multiple similar tumors; and tumors penetrating into the ventricle, but for which performed or potential endoscopic pathway did not pass through the ventricle (e.g., skull base tumors for transsphenoidal biopsy and some cystic tumors near the ventricles).

\section{Surgical technique}

The type of biopsy approach was based on the decision of the neurosurgical team. Imaging tests, personal preferences, and medical history (e.g., previous hydrocephalus treatment) affected the decision. For surgical planning, all patients were evaluated with magnetic resonance imaging (MRI). Stereotactic biopsies were usually performed under local anesthesia using a 4-pin stereotactic frame and BrainLab software with automatic CT/MRI image fusion. Microforceps were used to obtain serial biopsy specimens. When other procedures were performed simultaneously with the biopsy, general anesthesia was used if necessary. Endoscopic biopsies were performed under general anesthesia using a $30^{\circ}$ endoscope (Minop, Aesculap). One or several samples of the tumor were obtained using forceps. Additional procedures, such as ventriculostomy or tumor cyst aspiration, were performed as needed. If the trajectories were significantly different, two separate burr holes were used for biopsy and ventriculostomy.

\section{Histopathology}

In most cases, a neuropathologist present in the operating room confirmed the presence of pathological tissue by smear preparation. The final histologic diagnosis was based on the World Health Organization classification system. Some patients underwent subsequent open surgery to remove the tumor. In these cases, the histologic diagnosis based on biopsy specimens was compared with the diagnosis based on the resection specimen.

\section{Follow-up}

Each patient underwent a postoperative CT scan within $24 \mathrm{~h}$ after surgery. They were then followed up on a regular basis, and their outcomes during the first 3 months postoperatively were analyzed.

\section{Statistical analysis}

Diagnostic rates and complication rates were compared between the two biopsy methods. Fisher's exact test was used to compare categorical factors. All $p$ values were two-tailed, and the significance level was set at 0.05 .

\section{Ethics considerations}

Written informed consent was obtained for surgery from all participants. Ethical approval and individual consent to participate in the study were waived by the Ethics Committee according to local regulations and the tenets of the Helsinki Declaration because of the retrospective nature of this study that had no impact on the routine care. 


\section{Results}

\section{Clinical features}

A total of 119 patients were included in the study. Their mean age was 47 years (range, 18-84 years). Detailed data regarding demographics, location of the biopsied lesion (intraventricular or paraventricular), and presence and severity of hydrocephalus are summarized in Table 1. A total of 120 tumors were considered suitable for biopsy, and 123 biopsies were performed: 85 stereotactic and 38 endoscopic. Four patients underwent both stereotactic and endoscopic biopsies. Two of these patients underwent stereotactic biopsy after nondiagnostic endoscopic biopsy. One patient had two different tumors in separate locations at different times (endoscopic biopsy in 2012, stereotactic biopsy in 2014). Another patient underwent simultaneous stereotactic biopsy and endoscopic third ventriculostomy (ETV), and because the tumor was clearly visible through the endoscope, samples were also obtained endoscopically. In 39 cases, additional procedures were performed at the same time as the biopsy (Table 2).

\section{Tumor pathology}

The histopathologic diagnoses are presented in Table 3. In 5 cases, the biopsy samples were designated as nondiagnostic (2 stereotactic, 3 endoscopic). Overall, the diagnostic yield was $98 \%$ for stereotactic biopsies and $92 \%$ for endoscopic biopsies. Eleven patients underwent subsequent surgical resection of their tumor. In 7 cases (4 stereotactic, 3 endoscopic), pathologic examination of the resection specimen confirmed the initial biopsy diagnosis, but in 4 cases ( 3 stereotactic, 1 endoscopic), there were discrepancies between the diagnoses. When the numbers of nondiagnostic samples and incorrect diagnoses were added together, the total nondiagnostic biopsy rate was $6 \%$ (5 cases) for stereotactic biopsies and 11\% (4 cases) for endoscopic biopsies. These rates were not significantly different between groups (Table 4).
Table 2 Additional intraoperative procedures

\begin{tabular}{llll}
\hline Procedures & Total & Stereotactic & Endoscopic \\
\hline All additional procedures & 39 & 5 & 35 \\
Endoscopic third ventriculostomy & 26 & 2 & 25 \\
Tumor cyst aspiration & 10 & 2 & 8 \\
Ventriculoperitoneal shunt & 1 & 0 & 1 \\
Septum pellucidotomy & 1 & 0 & 1 \\
Rickham reservoir placement & 1 & 0 & 1 \\
\hline
\end{tabular}

\section{Complications}

Complications occurred in 14 patients (11\%): $10(12 \%)$ in the stereotactic group and $4(11 \%)$ in the endoscopic group (Table 5). Three bleeding episodes occurred within the first $24 \mathrm{~h}$ after biopsy. Two cases of delayed bleeding leading to death occurred within 1 month after biopsy of intraventricular tumors: 1 after stereotactic biopsy of a metastatic tumor and 1 after endoscopic biopsy of an ependymoma II. One patient developed severe, increasing brain edema with a fatal outcome on the third day after stereotactic biopsy of a larger, inoperable thalamic tumor (glioblastoma). Except for the complications resulting in death, all complications resolved with no permanent sequelae. There were no statistically significant differences in rates of complications or death between stereotactic and endoscopic groups.

During follow-up, 6 patients required additional surgery for hydrocephalus because of disease progression. All 6 of these patients had undergone stereotactic biopsy, although the rate of additional complications was not significantly different between groups (Table 5). There were no complications after the additional operations or other adverse consequences during the observation period.

The overall mortality rate was $2.4 \%$ for the 119 patients with lesions in the ventricular area. This was significantly higher than the $0.3 \%$ mortality rate for all 1581 patients undergoing biopsy of intracranial lesions at any location during the study period ( $p=0.016$; Table 6$)$.
Table 1 Patient characteristics $(N=119)$

\begin{tabular}{llll}
\hline Characteristics & Total & Stereotactic & Endoscopic \\
\hline Number of biopsies & 123 & 85 & 38 \\
Males/females & $57 / 62$ & $42 / 43$ & $17 / 21$ \\
Age, years & $47(18-84)$ & $48(18-78)$ & $45(18-84)$ \\
Paraventricular tumor & 95 & 76 & 22 \\
Intraventricular tumor & 25 & 9 & 16 \\
Hydrocephalus at initial diagnosis & & & 32 \\
Significant hydrocephalus & 73 & 45 & 3 \\
Mild enlargement of ventricles or part of a ventricle & 27 & 24 & 3 \\
No ventricular dilation & 19 & 16 & \\
\hline
\end{tabular}

Data are number or mean (range) 
Table 3 Distribution of pathological diagnoses

\begin{tabular}{llll}
\hline Histologic diagnoses & Total & Stereotactic & Endoscopic \\
\hline Glioblastoma & 25 & 23 & 2 \\
Anaplastic astrocytoma III & 21 & 16 & 5 \\
Glioma malignum, nonspecified & 2 & 2 & 0 \\
Astrocytoma II & 8 & 6 & 2 \\
Astrocytoma pilocyticum I & 1 & 0 & 1 \\
Oligodendroglioma II & 1 & 1 & 0 \\
Oligoastrocytoma II & 1 & 1 & 0 \\
Ganglioglioma I & 1 & 0 & 1 \\
Anaplastic ependymoma III & 5 & 4 & 1 \\
Ependymoma II & 10 & 7 & 3 \\
Lymphoma & 16 & 14 & 2 \\
Metastasis & 7 & 4 & 3 \\
Craniopharyngioma & 2 & 0 & 2 \\
Germinoma & 2 & 0 & 2 \\
Pineoblastoma III & 1 & 1 & 0 \\
Pineocytoma I & 1 & 0 & 1 \\
Papillary tumor of pineal region III & 1 & 0 & 1 \\
Medulloblastoma & 1 & 1 & 0 \\
Colloid cyst & 4 & 1 & 3 \\
Glial cyst & 3 & 0 & 3 \\
Toxoplasmosis & 1 & 1 & 0 \\
Inflammation, nonspecified & 1 & 0 & 1 \\
Brain infarct & 1 & 1 & 0 \\
No significant pathology & 2 & 0 & 2 \\
Nondiagnostic samples & 5 & 2 & 3 \\
\hline & & & \\
\hline
\end{tabular}

\section{Discussion}

\section{Literature review}

An intensive PubMed search revealed that in recent publications, reports of endoscopic methods have dominated the topic of biopsies for pathology in the region of the ventricular system. Many of these reports, including the largest multicenter study [5], mention numerous advantages of endoscopic biopsies over stereotactic biopsies, especially for intraventricular tumors. The literature therefore suggests that endoscopic biopsies are better options than stereotactic biopsies, and a few of us also prefer the endoscopic technique. However, these preferences are based primarily on intuition, as no published study has confirmed the advantages of one method over the other for tumors involving the ventricular system.

Stereotactic and endoscopic biopsies have been compared in large groups of patients only for pineal tumors. Somewhat unexpectedly, the studies by Balossier et al. [3, 4] demonstrated slightly superior effectiveness and safety with stereotactic biopsies for pineal tumors. Kinfe et al. [16] compared biopsy approaches for only paraventricular tumors, but their study was confounded by selection bias (e.g., the stereotactic group included cases considered unsuitable for endoscopic biopsy). Therefore, conclusions from that study are of limited value. Although many papers reported the results of intracranial stereotactic biopsies, including papers involving very large groups (i.e., thousands) of patients $[9,14,20,22]$, these publications either did not report the results for tumors involving the ventricles or included very small numbers of patients with tumors in this region. We identified only a few papers containing more than 10 cases of para- and intraventricular lesions $[1,2,7,8,10,16,27]$. Livermore et al. [18]. reported only that there was a significant increase in hemorrhage rate with biopsies of deep versus superficial intracranial tumors. Because of the small amount of data and inconsistency between study results, no metaanalysis has been performed comparing biopsy methods for intracranial tumors involving the ventricles.

\section{Case selection}

In this study, we included only cases considered suitable for either type of biopsy at the time of the initial diagnosis. The type of biopsy actually performed was not randomized but depended on the neurosurgeon's individual decision. Selection bias remains a possibility in our study. After their initial diagnosis, some patients included in the study were effectively treated for hydrocephalus at other hospitals before being referring to our institution for biopsy, and at that time, endoscopic biopsy was no longer recommended. However, if the tumor had been considered suitable for both biopsies at the time of the original diagnosis, then the patient was included in the study. Because of this, there were more stereotactic than endoscopic biopsies in the current study.

An original objective of this study was to perform separate comparisons for intraventricular and paraventricular tumors. However, the number of cases in the intraventricular group was small, prohibiting separate evaluations.
Table 4 Analysis of nondiagnostic biopsies

\begin{tabular}{lllll}
\hline Histologic results & Total & Stereotactic & Endoscopic & $P$ value \\
\hline Nondiagnostic samples & 5 & 2 & 3 & - \\
Misdiagnosis & 4 & 3 & 1 & - \\
Total nondiagnostic biopsies & $9(7 \%)$ & $5(6 \%)$ & $4(11 \%)$ & 0.456 \\
\hline
\end{tabular}


Table 5 Postoperative complications

\begin{tabular}{lllll}
\hline Complications & $\begin{array}{l}\text { Total } \\
\text { (out of } \\
123)\end{array}$ & $\begin{array}{l}\text { Stereotactic } \\
\text { (out of 85) }\end{array}$ & $\begin{array}{l}\text { Endoscopic } \\
\text { (out of 38) }\end{array}$ & $\begin{array}{l}P \\
\text { value }\end{array}$ \\
\hline $\begin{array}{l}\text { Early }(<24 \text { h) postoperative intraventricular hemorrhage, } \\
\text { resolved spontaneously }\end{array}$ & 1 & 1 & 0 & 1 \\
$\begin{array}{l}\text { Early }(<24 \text { h) epidural hematoma in the area of biopsy } \\
\quad \text { rajectory, required surgery }\end{array}$ & 1 & 1 & 0 & 1 \\
$\begin{array}{l}\text { Early }(<24 \text { h) intracerebral hematoma outside the biopsy } \\
\text { area (in the cerebellum), resolved spontaneously }\end{array}$ & 1 & 0 & 1 & 0.309 \\
$\begin{array}{l}\text { Delayed }(>48 \text { h) intraventricular hemorrhage, resulting } \\
\text { in death }\end{array}$ & 2 & 1 & 1 & 0.524 \\
Total significant bleeding (early or delayed) & 5 & 3 & 2 & 0.644 \\
Brain swelling, resulting in death & 1 & 1 & 0 & 1 \\
New seizures & 3 & 3 & 0 & 0.552 \\
Transient confusion and memory deficit $(<7$ days) & 2 & 1 & 1 & 0.524 \\
Transient mild hemiparesis & 1 & 1 & 0 & 1 \\
Superficial wound infection & 1 & 1 & 0 & 1 \\
Urinary infection & 1 & 0 & 1 & 0.309 \\
Total morbidity & 14 & 10 & 4 & 1 \\
Total mortality & 3 & 2 & 1 & 1 \\
Hydrocephalus required treatment within 1 month after & 6 & 6 & 0 & 0.176 \\
$\quad$ biopsy & & & & \\
\hline
\end{tabular}

\section{Histopathology}

In 2 cases, the histopathologic diagnosis was "no significant pathology". It was uncertain whether these were diagnostic or nondiagnostic biopsies; nevertheless, the tissue samples were adequate for histopathologic evaluation, control imaging studies confirmed the site of collection within the radiologic lesion, and the lesions did not change during further follow-up. Therefore, we considered the diagnosis to be accurate and classified these cases as diagnostic.

In addition to histopathologic examination, molecular studies have been recently introduced for tumor assessment. However, results of these studies were available for only some of the tumors evaluated in this study, so we did not include these findings in our analyses.

\section{Complications}

The 2 patients with delayed intraventricular bleeding displayed very similar postoperative courses. Their CT scans on the day after biopsy showed only a small amount of blood in the ventricles, with no neurologic sequelae. This bleeding was therefore considered nonserious. However, the neurologic status of both patients began to deteriorate more than 2 days after the biopsy, and subsequent $\mathrm{CT}$ examinations showed gradually increasing blood volume in the ventricles. Extraventricular drains were inserted, but despite this treatment, the neurologic status of both patients continued to worsen, leading to death within a month. These deaths could possibly have been prevented with more aggressive treatment, such as resection of the bleeding tumor.

\section{Additional procedures}

The advantages and disadvantages of both biopsy methods are well known. Perhaps the most important advantage of the endoscopic method is the ability to perform other procedures during the same operation as the biopsy. In our study, hydrocephalus treatment and tumor cyst aspiration were performed more frequently with endoscopic biopsies, resulting in a reduction of intracranial mass effects. Thus, endoscopic biopsies were often therapeutic, as well as diagnostic. If additional procedures were not performed, the risk of endoscopic biopsies themselves may have been lower. On the other hand,
Table 6 Mortality rates after biopsy of intracranial lesions in the ventricular area and intracranial lesions in all locations

\begin{tabular}{llll}
\hline Biopsies and deaths & All intracranial biopsies & Intra- and paraventricular biopsies & $P$ value \\
\hline Number of biopsies & 1581 & 123 & - \\
All biopsy-related deaths & $5(0.3 \%)$ & $3(2.4 \%)$ & 0.016 \\
\hline
\end{tabular}


however, for stereotactic biopsies, the cumulative risk of ventriculoperitoneal shunt placement and biopsies was not higher than the risks associated with the biopsies themselves, as we did not observe any shunt-related complications in the stereotactic biopsy group. It is possible that the main benefit of combining procedures is the shorter duration of entire treatment. Especially in cases of hydrocephalus occurring within a month of biopsy, oncologic treatment was unnecessarily delayed. In at least some of these cases, ETV could have been performed prophylactically if endoscopic biopsy had been used. Nonetheless, it would be difficult to design a study evaluating the effects of biopsy method on treatment duration because of the many confounding variables that would be involved.

\section{Limitations}

The limitations of the study are its retrospective character, selection bias due to the choice of the biopsy type by the surgeon, evaluation of the results from only one center, and only one of the different types of stereotactic biopsies was used. In our department, we routinely use microforceps for stereotactic biopsies. We used side-cutting needle and spiral needle in only a few specific cases in other areas. In the ventricular area we prefer to use microforceps because the side-cutting needle requires a longer trajectory which increases the risk of puncture the ependyma. There is not enough evidence to conclude that one tool is significantly better than the other. Nevertheless, we cannot exclude that the choice of biopsy method affects the results. Kreth et al. in 2001 [17] published a very low complication rate and very high diagnostic rate using microforceps. On the other hand the use of a side-cutting needle has been reported more frequently in recent years, but this trend is not supported by scientific evidence, but only by some opinions [21]. We can only find a comparison of tissue collection methods in a very small study of AIDS patients [13] and of dead pig brains [25]. In meta-analyzes $[9,11,15]$ and systemic review [22] the results were not compared depending on the method of tissue collection during stereotactic biopsies. The neurosurgeons participating in this study usually perform frame-based biopsies, instead of navigational, frameless biopsies. Consequently, only frame-based cases were included in the stereotactic biopsy group. However, the results are likely generalizable to all types of stereotactic biopsies, as previous studies confirmed that effectiveness and safety are not significantly different between stereotactic frameless and frame-based needle biopsies $[6,19,23,26]$.

\section{Conclusions}

The mortality rate was higher after biopsies of intracranial tumors involving the ventricles than after biopsies of all intracranial tumors (in any location). The rates of total nondiagnostic biopsies and complications after endoscopic and stereotactic brain biopsies in the ventricle area were similar. The only possible, but not fully confirmed, advantage of endoscopic biopsies over stereotactic biopsies is the ability to simultaneously treat hydrocephalus and thereby shorten the time for determining the pathologic diagnosis and treating hydrocephalus.

Authors' contributions All authors contributed to the study conception and design. All authors read and approved the final manuscript. Leading roles in particular stages of preparation of the study are the following: conceptualization, Marcin Birski; methodology, Marcin Birski, Jacek Furtak, Kamil Krystkiewicz, and Julita Birska; literature review, Marcin Birski, Kamil Krystkiewicz, and Julita Birska; data collection and analysis, Marcin Birski, Jacek Furtak, Kamil Krystkiewicz, Julita Birska, Karolina Zielińska, Paweł Sokal, Marcin Rusinek, Dariusz Paczkowski, and Lukasz Szylberg, writing: Marcin Birski; and review and supervision, Marek Harat.

Funding This work was not supported by any funds from any sponsors or organizations.

Data Availability All collected data can be made available on a reasonable request.

\section{Compliance with ethical standards}

Conflict of interest The authors declare that they have no conflict of interest.

Conflict of interest All authors have no relevant financial or nonfinancial relationships to disclose.

Ethics approval and consent to participate Written informed consent was obtained for surgery from all participants. Ethical approval and individual consent to participate in the study were waived by the Ethics Committee of Collegium Medicum Nicolaus Copernicus University in Bydgoszcz according to local regulations and the tenets of the Helsinki Declaration because of the retrospective nature of this study that had no impact on the routine care.

Consent for publication Not applicable.

Code availability (software application or custom code) Not applicable.

Open Access This article is licensed under a Creative Commons Attribution 4.0 International License, which permits use, sharing, adaptation, distribution and reproduction in any medium or format, as long as you give appropriate credit to the original author(s) and the source, provide a link to the Creative Commons licence, and indicate if changes were made. The images or other third party material in this article are included in the article's Creative Commons licence, unless indicated otherwise in a credit line to the material. If material is not included in the article's Creative Commons licence and your intended use is not permitted by statutory regulation or exceeds the permitted use, you will need to obtain permission directly from the copyright holder. To view a copy of this licence, visit http://creativecommons.org/licenses/by/4.0/.

\section{References}

1. Apuzzo ML, Chandrasoma PT, Cohen D, Zee CS, Zelman V (1987) Computed imaging stereotaxy: experience and perspective 
related to 500 procedures applied to brain masses. Neurosurgery. 20(6):930-937

2. Apuzzo ML, Chandrasoma PT, Zelman V, Giannotta SL, Weiss MH (1984) Computed tomographic guidance stereotaxis in the management of lesions of the third ventricular region. Neurosurgery. 15(4):502-508

3. Balossier A, Blond S, Reyns N (2016) Endoscopic versus stereotactic procedure for pineal tumor biopsies: focus on overall efficacy rate. World Neurosurg 92:223-228. https://doi.org/10.1016/j.wneu. 2016.03.088

4. Balossier A, Blond S, Touzet G, Lefranc M, de Saint-Denis T, Maurage CA, Reyns N (2015) Endoscopic versus stereotactic procedure for pineal tumour biopsies: comparative review of the literature and learning from a 25-year experience. Neurochirurgie. 61(2-3):146-154. https://doi.org/10.1016/j.neuchi.2014.06.002

5. Constantini S, Mohanty A, Zymberg S, Cavalheiro S, Mallucci C, Hellwig D, Ersahin Y, Mori H, Mascari C, Val JAC, Wagner W, Kulkarni AV, Sgouros S, Oi S (2013) Safety and diagnostic accuracy of neuroendoscopic biopsies: an international multicenter study. J Neurosurg Pediatr 11(6):704-709. https://doi.org/10. 3171/2013.3.PEDS12416

6. Dammers R, Haitsma IK, Schouten JW, Kros JM, Avezaat CJ, Vincent AJ (2008) Safety and efficacy of frameless and framebased intracranial biopsy techniques. Acta Neurochir 150:23-29

7. Field M, Witham TF, Flickinger JC, Kondziolka D, Lunsford LD (2001) Comprehensive assessment of hemorrhage risks and outcomes after stereotactic brain biopsy. J Neurosurg 94(4):545-551

8. Grossman R, Sadetzki S, Spiegelmann R, Ram Z (2005) Haemorrhagic complications and the incidence of asymptomatic bleeding associated with stereotactic brain biopsies. Acta Neurochir 147(6):627-631 discussion 631

9. Hall WA (1998) The safety and efficacy of stereotactic biopsy for intracranial lesions. Cancer 82:1749-1755

10. Hamisch C, Blau T, Klinger K, Kickingereder P, Ruess D, Galldiks N, Berthold F, Simon T, Grau S, Ruge M (2017) Feasibility, risk profile and diagnostic yield of stereotactic biopsy in children and young adults with brain lesions. Klin Padiatr 229(3):133-141. https://doi.org/10.1055/s-0043-101908

11. Hamisch C, Kickingereder P, Fischer M, Simon T, Ruge MI (2017) Update on the diagnostic value and safety of stereotactic biopsy for pediatric brainstem tumors: a systematic review and meta-analysis of 735 cases. J Neurosurg Pediatr 20(3):261-268. https://doi.org/ 10.3171/2017.2.PEDS1665

12. Hayashi N, Murai H, Ishihara S, Kitamura T, Miki T, Miwa T, Miyajima M, Nishiyama K, Ohira T, Ono S, Suzuki T, Takano S, Date I, Saeki N, Endo S (2011) Nationwide investigation of the current status of therapeutic neuroendoscopy for ventricular and paraventricular tumors in Japan. J Neurosurg 115(6):1147-1157. https://doi.org/10.3171/2011.7.JNS101976

13. Hirschfeld A, Pellegrin K, Rawanduzy A (1994) Stereotactic brain biopsies in AIDS patients: superior diagnostic yield with sidecutting needle than with cup forceps. Stercotact Funct Ncurosurg 63:150-153. https://doi.org/10.1159/000100307

14. Johnson DR, O'Neill BP, Decker PA, Kosel ML, Lanzino G, Hammack JE (2013) Mortality and discharge to home after closed brain biopsy: analysis of 3523 cases from the State of California, 2003-2009. World Neurosurg 79(1):110-115. https://doi.org/10. 1016/j.wneu.2012.03.033
15. Kickingereder P, Willeit P, Simon T, Ruge MI (2013) Diagnostic value and safety of stereotactic biopsy for brainstem tumors: a systematic review and meta-analysis of 1480 cases. Neurosurgery 72 : 873-882. https://doi.org/10.1227/NEU.0b013e31828bf445

16. Kinfe TM, Capelle HH, Mirzayan MJ, Boschert J, Weigel R, Krauss JK (2011) Stereotactic versus endoscopic surgery in periventricular lesions. Acta Neurochir 153(3):517-526. https:// doi.org/10.1007/s00701-010-0933-x

17. Kreth FW, Muacevic A, Medele R, Bise K, Meyer T, Reulen HJ (2001) The risk of haemorrhage after image guided stereotactic biopsy of intra-axial brain tumours - a prospective study. Acta Neurochir 143:539-546

18. Livermore LJ, Ma R, Bojanic S, Pereira EA (2014) Yield and complications of frame-based and frameless stereotactic brain biopsythe value of intra-operative histological analysis. Br J Neurosurg 28(5):637-644. https://doi.org/10.3109/02688697.2014.887657

19. Lu Y, Yeung C, Radmanesh A, Wiemann R, Black PM, Golby AJ (2015) Comparative effectiveness of frame-based, Frameless and Intraoperative MRI Guided Brain Biopsy Techniques. World Neurosurg 83(3):261-268

20. Malone H, Yang J, Hershman DL, Wright JD, Bruce JN, Neugut AI (2015) Complications following stereotactic needle biopsy of intracranial tumors. World Neurosurg 84(4):1084-1089. https://doi.org/ 10.1016/j.wneu.2015.05.025

21. Owen CM, Linskey ME (2009) Frame-based stereotaxy in a frameless era: current capabilities, relative role, and the positiveand negative predictive values of blood through the needle. $\mathrm{J}$ Neuro-Oncol 93:139-149. https://doi.org/10.1007/s11060-0099871-y

22. Riche M, Amelot A, Peyre M, Capelle L, Carpentier A, Mathon B (2020) Complications after frame-based stereotactic brain biopsy: a systematic review. Neurosurg Rev. https://doi.org/10.1007/s10143019-01234-w

23. Smith JS, Quiñones-Hinojosa A, Barbaro NM, McDermott MW (2005) Frame-based stereotactic biopsy remains an important diagnostic tool with distinct advantages over frameless stereotactic biopsy. J Neuro-Oncol 73:173-179

24. Somji M, Badhiwala J, McLellan A, Kulkarni AV (2016) Diagnostic yield, morbidity, and mortality of intraventricular neuroendoscopic biopsy: systematic review and meta-analysis. World Neurosurg 85:315-324.e2. https://doi.org/10.1016/j.wneu. 2015.09.011

25. Trojanowski P, Jarosz B, Szczepanek D (2019) The diagnostic quality of needle brain biopsy specimens obtained with different sampling methods - experimental study. Sci Rep 9:8077. Published online 2019 May 30, PMC6542833. https://doi.org/10.1038/ s41598-019-44622-4

26. Woodworth GF, McGirt MJ, Samdani A et al (2006) Frameless image-guided stereotactic brain biopsy procedure: diagnostic yield, surgical morbidity, and comparison with the frame-based technique. J Neurosurg 104:233-237

27. Yu X, Liu Z, Tian Z, Li S, Huang H, Xiu B, Zhao Q, Liu L, Jing W (2000) Stereotactic biopsy for intracranial space-occupying lesions: clinical analysis of 550 cases. Stereotact Funct Neurosurg 75(2-3): 103-108

Publisher's note Springer Nature remains neutral with regard to jurisdictional claims in published maps and institutional affiliations. 